\title{
CULTURA ORGANIZACIONAL GRANDES TEMAS EM DEBATE*
}

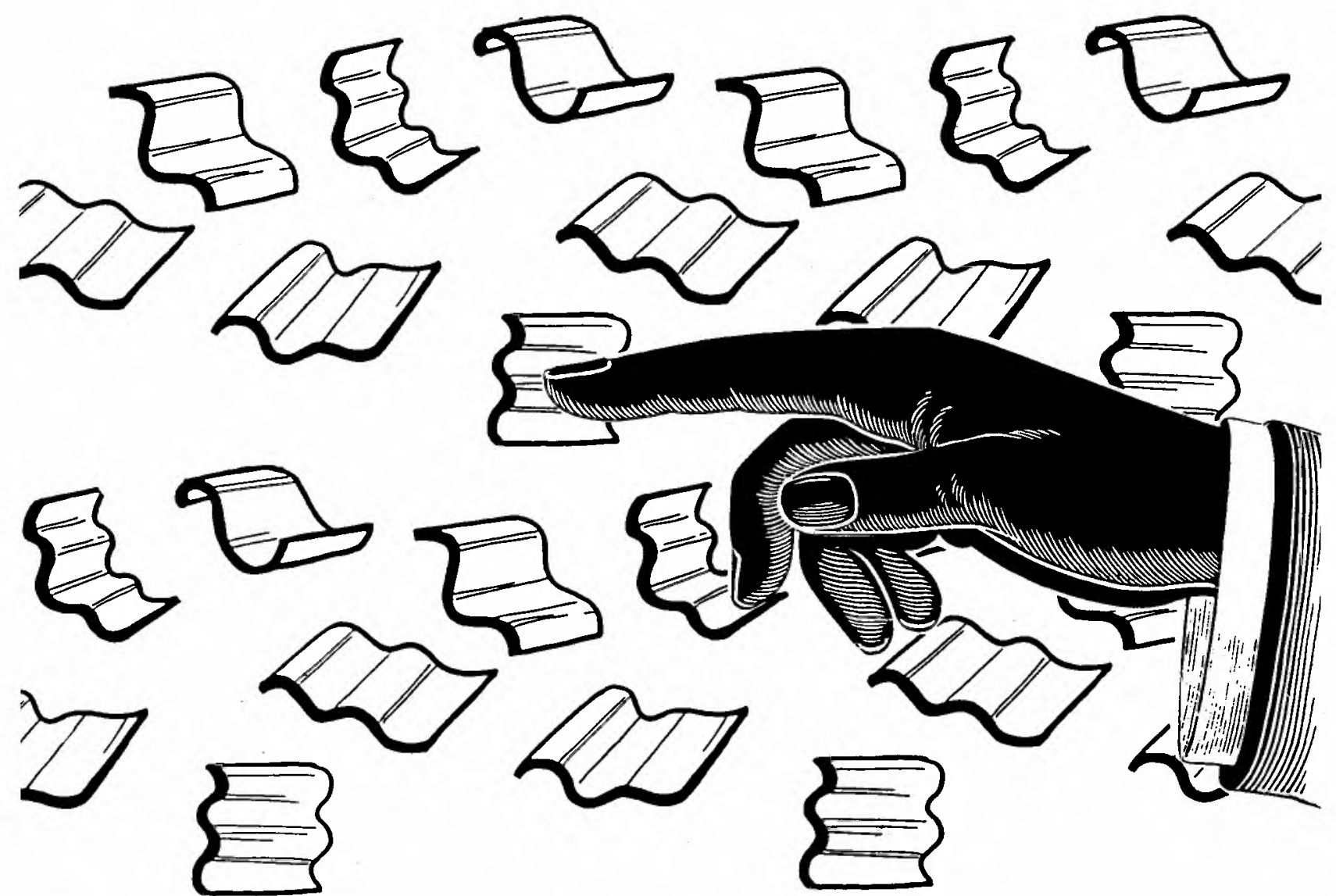

Maria Ester de Freitas

Professora do Departamento de Administração da Universidade Federal de Uberlândia. Mestre em Administração de Empresas pela EAESP/FGV.

* RESUMO: Este texto reconstitui a bibliografia norteamericana, a partir de 1979, situando os tópicos que receberam maior destaque por parte de acadêmicos e consultores organizacionais. Agrupa sob um mesmo título várias opiniōes, indicando diversos aspectos investigados em pesquisas empíricas. Detalha conceitos e levanta algumas interrogações sobre os conteúdos ideológicos implícitos nos estudos citados.

* PALAVRAS CHAVE: Cultura organizacional, simbolismo organizacional, ideologia, análise organizacional.
* ABSTRACT: This paper addresses a brief review of the main issues that have been studied on Organizational Culture.

The focus is on questions to which academic researchers and organizational consultants have drawn their attention. It puts on the same title some different points of view and raises some questions about ideological contents of the studies mentioned.

The study is anchored to the north-american findings research produced from 1979 on, containing a set of 148 articles and 15 books together.

* KEY WORDS: Organizational culture, organizational simbolism, ideology, analysis of organizations.

* Este texto é uma síntese da Dissertação de Mestrado da autora, com o mesmo título, defendida na EAESP/FGV em 30.10.89. 


\section{INTRODUÇÃO}

A

Teoria das Organizações vem dando ênfase crescente ao tema Cultura Organizacional. Embora presente na literatura anterior à década de 80 , a maior incidência de pesquisas, conferências, cursos, publicações etc. começa a ocorrer a partir de 1983, quando as revistas Administrative Science Quarterly e Organizational Dynamics dedicaram edições especiais ao assunto ${ }^{1}$.

Curiosamente, a discussão sobre a Cultura Organizacional vem ocorrendo não apenas nos limites da academia, mas também nas páginas da grande imprensa².

Por que o grande interesse pela questão cultural nas organizações cresceu só nos anos oitenta, se ela já estava presente na produção acadêmica anterior ${ }^{3}$ ? É interessante notar que, já na primeira metade deste século, o Sr. Tom Watson pregava os valores e crenças da IBM; que, em 1913, a J.C.Penny formulou o seu credo, onde enfatizava que uma vitória rápida era menos importante que a construção de uma lealdade a longo prazo; que o credo da Johnson \& Johnson data de 1940.

Poucos são os autores que se arriscaram a explicar a razão desse interesse súbito. Nestes poucos ${ }^{4}$, a argumentação mais comumente encontrada relaciona-se ao recente declínio da produtividade norte-americana e ao ganho de competitividade dos japoneses. O milagre japonês tem inspirado vários best-sellers e muitas organizações têm contratado serviços de consultoria para aplicar as técnicas que fazem o sucesso japonês. Esse tipo de transposição tem levantado as diferenças entre as duas sociedades, onde o Japão aparece como mais homogêneo, com visão holística e ênfase no coletivo.

Numa explicação diferente, Mats Alvesson 5 admite que a popularidade do tema pode ser atribuída em parte ao milagre japonês, porém não reconhece que os problemas puramente econômicos possam explicar o porquê do grande interesse pelos aspectos culturais e simbólicos nas organizações. Apoiado no pressuposto de que a Teoria das Organizações tem sido influenciada ideologicamente pela perspectiva gerencial, sugere

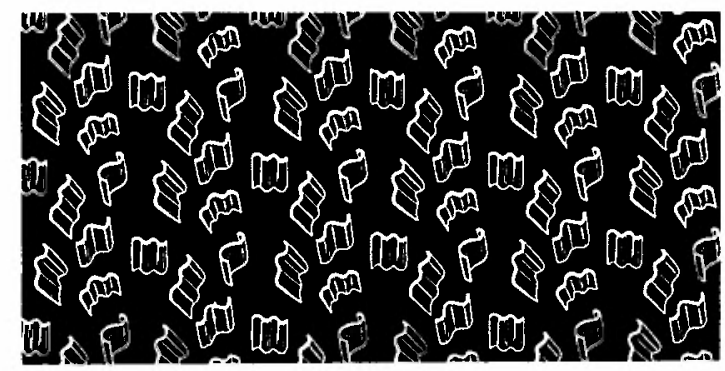

que as pesquisas realizadas nessa área são, em grande parte, respostas a problemas práticos identificados pelas gerências. Para Alvesson, o desenvolvimento acelerado dos últimos dez ou vinte anos tem resultado num processo de quebra da uniformidade e cõesão dos padrões culturais. Essas tendências têm produzido uma fragmentação e heterogeneidade, onde a interação social aparece como problemática, evidenciando a necessidade de aperfeiçoamento do conteúdo das ideologias e/ou dos fundamentos em que elas estão baseadas. A cultura organizacional surge como um contra-ataque aos problemas de desintegração da sociedade, como uma solução atraente, enfatizando as idéias comuns, formas de pensar, valores, padrões e maneiras de trabalhar. Assim, a cultura organizacional fornece a resposta a essas tendências de desagregação social pela quebra dos padrões culturais, reproduzindo uma ordem particular, via consenso e solidariedade entre os membros da organização.

Compartilhamos da opinião de Alvesson e vemos a cultura organizacional como um poderoso mecanismo de controle, que visa a conformar condutas, homogeneizar maneiras de pensar e viver a organização, introjetando uma imagem positiva dela, onde todos são iguais, escamoteando as diferenças e conflitos inerentes a um sistema que guarda um antagonismo e anulando a reflexão.

Neste trabalho, pretendemos apresentar, mais ou menos sucintamente, os tópicos que têm recebido maior atenção de pesquisadores acadêmicos e consultores organizacionais. Os pontos escolhidos foram baseados no levantamento da bibliografia norte-americana, principalmente, de 1979 a 1989, sendo utilizados 148 artigos e quinze livros. Não pretendemos fazer uma avaliação crítica dos diversos subtemas - ainda que façamos alguns comentários esporádicos sobre um ou outro tópico - mas visamos a apresentar a maneira como $o$ assunto vem sendo debatido.

\section{A QUESTÃO CONCEITUAL}

A discussão em torno da cultura organizacional vem seguindo uma base de conceitos fornecida pela Antropologia Cultural, onde existem diversas correntes teóricas, que privilegiam aspectos diferentes de um mesmo fenômeno.

Para efeitos deste trabalho, adotamos o conceito apresentado por Schein ${ }^{6}$, que consideramos um dos mais ricos na literatura consultada. A Cultura Organizacional é o modelo dos pressupostos básicos, que um dado grupo inventou, descobriu ou desenvolveu no 
processo de aprendizagem, para lidar com os problemas de adaptação externa e integração interna. Uma vez que os pressupostos tenham funcionado bem o suficiente para serem considerados válidos, eles são ensinados aos demais membros da organização como a maneira certa de se perceber, pensar e sentir em relação àqueles problemas.

\section{ALGUNS ELEMENTOS DA CULTURA ORGANIZACIONAL}

A descrição dos elementos que constituem a cultura organizacional, a forma como eles funcionam e, ainda, as mudanças que eles provocam no comportamento são maneiras de dar ao assunto um tratamento mais concreto e de mais fácil identificação. Nesse sentido, é bastante comum encontrarmos a cultura sendo conceituada a partir dos. seus próprios elementos.

Verificamos que, no todo ou em parte, esses elementos fornecem uma interpretação para os membros da organização, onde a passagem dos significados se dá como uma coisa aceita. A linguagem é funcionalizada, restando a aceitação do que é oferecido como é oferecido. De certa forma, isso sugere a presença de um componente hipnótico, através do qual as mensagens e comportamentos convenientes são objeto de aplauso e adesão, levando à naturalização do seu conteúdo e à transmissão espontânea aos demais membros. Tanto a adesão como a reprodução demonstram não a liberdade dos indivíduos de os aceitar ou não, mas a eficiência do controle embutido. são:

Os elementos mais freqüentemente citados

a) Valores: definições a respeito do que é importante para se atingir o sucesso. Observa-se que, em geral, as empresas definem alguns poucos valores, que resistem ao teste do tempo, os quais são constantemente enfatizados. Ainda que elas tendam a personalizar os seus valores, podemos verificar que eles guardam algumas características comuns: importância do consumidor, padrão de desempenho excelente, qualidade e inovação, importância da motivação intrínseca etc.

b) Crenças e pressupostos: geralmente usados como sinônimos para expressar aquilo que é tido como verdade na organização. Quando um grupo ou organização resolve seus problemas coletivos, esse processo inclui alguma visão de mundo, algum mapa cognitivo, algumas hipóteses sobre a realidade e a natureza humana. Se o sucesso ocorre, aquela visão de mundo passa a ser considerada válida. Os pressupostos tendem a tornar-se inconscientes e inquestionáveis.

c) Ritos, rituais e cerimônias: são exemplos de atividades planejadas que têm conseqüências práticas e expressivas, tornando a cultura mais tangível e coesa. Exemplos dessas atividades constituem grande parte do que é desenvolvido pelos Departamentos de Recursos Humanos; como nos casos de admissão, promoção, integração, demissão etc.

d) Estórias e mitos: enquanto as estórias são narrativas de eventos ocorridos que informam sobre a organização, os mitos referem-se a estórias consistentes com os valores organizacionais, porém sem sustentação nos fatos. Ambos elementos preenchem funções específicas, tais como: mapas, símbolos, scripts etc.

e) Tabus: demarcam as áreas de proibições, orientando o comportamento com ênfase no não-permitido. A literatura consultada não dá maior atenção ao assunto, preferindo deter-se em casos de tragédias organizacionais e sugerindo formas de se lidar com elas.

f) Heróis: personagens que incorporam os valores e condensam a força da organização. Fala-se dos heróis natos e dos criados. É comum as organizações chamadas culturas fortes exibirem os seus heróis natos, como: Tom Watson, da IBM; John Rockefeller, da Standard Oil; Henry Ford, da Ford, entre outros.

g) Normas: as regras que defendem o comportamento que é esperado, aceito e sancionado pelo grupo, podendo estar escritas ou não.

h) Processo de comunicação: inclui uma rede de relações e papéis informais que comportam padres, fofoqueiros, conspiradores, contadores de estórias etc. Ele desenvolve funções importantes como a de transformar o corriqueiro em algo brilhante, podendo ser usado na administração da cultura.

\section{DESENVOLVIMENTO, MANUTENCÃO E IDENTIFICAÇÃO DA CULTURA}

Esses aspectos estão diretamente relacionados ao que os autores entendem por cultura. Escolhemos as proposições de Schein ${ }^{7}$ e Dyer $\mathrm{Jr}^{8}{ }^{8}$ sobre o desenvolvimento e manutenção, e as análises de Vijay Sathe ${ }^{9}$ e Deal e Kennedy ${ }^{10}$ sobre a identificação cultural.

Schein propõe um modelo dinâmico para a análise da formação da Cultura. Considera
7. SCHEIN, Edgard. "How Culture Forms, Develops and Changes". Op. cit.

8. DYER JR., W. G. "The Cycle of Cultural Evolution in Organizations. In: KILMANN, R. et alii. Op. cit.

9. SATHE, Vijay. "How to Decipher and Change Corporate Culture" in KILMANN, R. et alii. Op. cit.

10. DEAL, T. \& KENNEDY, A. Op cit. 
algumas definições que as organizações fazem para manejar os seus ambientes interno e externo, e que incluem:

a) senso de missão, razão de ser de sua existência;

b) alguns objetivos concretos derivados da missão;

c) sentido de realização através de estruturas e processos;

d) sentido de acompanhamento; $\mathrm{e}$

e) sentido de reparo.

Para que essas definições funcionem, todo grupo deve ter:

1. linguagem comum e categorias conceituais compartilhadas;

2. algum modo de definir suas fronteiras $e$ selecionar seus membros;

3. alguma forma de alocar autoridade e status; 4. normas para lidar com as relações interpessoais e íntimas;

5. critérios de recompensas e punições; e

6. alguma forma de lidar com o não-administrável.

Trabalhando com a hipótese segundo a qual a cultura é transmitida basicamente a partir dos mecanismos de redução de ansiedade/dor e de reforço/recompensa, Schein acredita que a pergunta sobre se "toda organização tem uma cultura" pode ser respondida em termos de oportunidade ou não para que a aprendizagem entre os seus membros ocorra. Ou, ainda, a cultura é diretamente proporcional à estabilidade do grupo, ao tempo que ele tem de convivência e à intensidade da aprendizagem gerada.

Quanto ao desenvolvimento cultural, está relacionado com o estágio de desenvolvimento da própria organização. Usando a noção de ciclo de vida, Schein atribui a seguinte correspondência:

\section{Fase de crescimento}

a) Nascimento e estágios iniciais de organização, onde existe a dominação do fundador ou da família dominante. A cultura é uma competência distinta e fonte de identificação, uma espécie de cimento que mantém os membros unidos. É dada uma forte ênfase à socialização como uma evidência compartilhada. b) Sucessão. A organização se torna um campo de batalha entre os conservadores e os progressistas. Sucessores potenciais são julgados de acordo com a sua capacidade de mudar alguns elementos da cultura presente.

2. Fase intermediária, com o desenvolvimento Cultura organizacional grandes temas em debate de novos produtos, integração vertical, expansão geográfica, aquisições, fusões etc. Surgem subculturas, crises de identidade, perda de objetivos-chave, valores e pressupostos. Oportunidade para mudança cultural.

3. Maturidade, com a estabilidade de mercados, falta de motivação para mudança. A cultura torna-se restritiva às inovações, passando a ser valorizada como uma fonte de auto-estima e defesa, preserva a glória do passado. Nesta fase, também pode ocorrer uma opção de transformação, via mudança cultural, ou uma opção de destruição, onde ocorre mudança cultural nos níveis básicos, através da substituição massiva de pessoas-chave.

Em Dyer Jr. encontramos um modelo de evolução cultural que considera, basicamente, o processo de resolução de crises e o papel das lideranças. Esse modelo é definido a partir de seis etapas:

a) se a crise percebida coloca em questionamento as habilidades e práticas das lideranças atuais;

b) se a percepção é acompanhada de uma ruptura nos padrões simbólicos, crenças e pressupostos;

c) se as novas lideranças emergem com um conjunto de novos pressupostos para resolver a crise;

d) existência de conflitos entre proponentes da antiga e nova liderança;

e) se a crise é resolvida e se os novos líderes são apontados como os responsáveis, estes, então, estabelecem-se como a nova elite cultural:

f) a cultura da nova liderança é sustentada pela introdução de novos modelos, até que o ciclo recomece em a).

Vijay Sathe compartilha as idéias de Schein sobre os níveis de definição da cultura e como esta se forma, comentando que uma melhor compreensão se dá quando se examinam os aspectos de conteúdo (pressupostos dos fundadores e líderes seguintes, bem como as experiências atuais de resolução de problemas e aprendizagem) e força (quão importantes são os pressupostos, quão largamente são compartilhados e a clareza de que alguns são mais importantes que outros).

Para decifrar a cultura, Sathe propõe:

1. inferir o seu conteúdo (as falas, as maneiras de fazer as coisas, os sentimentos compartilhados);

2. atentar para as qualificações e status dos investigadores (vantagens e desvantagens da 
observação dos antigos e recém-admitidos na organização);

3. estimar a força da cultura, observando a proporção em que seus membros compartilham manifestações, tais como: atributos físicos, slogans, práticas, expressões de sentimentos etc.

Já Deal e Kennedy sugerem dois tipos de análise: externa e interna. $\mathrm{Na}$ primeira:

a) observa-se o ambiente físico que sugere quão orgulhosa uma organização é de si própria;

b) lê-se o que a companhia fala sobre si e sua cultura;

c) testa-se como a companhia recebe os estranhos;

d) entrevistam-se pessoas a respeito da história da companhia, como foi o seu começo, que tipo de pessoas trabalha ali, quem vai avante, a que se atribui o sucesso.

$O$ aspecto interno envolve entender questões como: o sistema de carreiras; quanto tempo, principalmente na administração média, as pessoas ficam num determinado cargo; qual o conteúdo dos discursos e memorandos; as anedotas e estórias que circulam na rede cultural. Aqui também podem ser detectados alguns males culturais - foco no curto prazo, explosões emocionais, fragmentação e inconsistências etc.

\section{ALGUMAS TIPOLOGIAS}

a) Charles Handy e Roger Harrison ${ }^{11}$, consideram a distribuição de poder dentro das organizações.

- cultura de poder (pequenas empresas centralização);

- cultura de papéis (organizações excessivamente bucrocratizadas);

- cultura de tarefa (ênfase na competência e perícia);

- cultura de pessoa (centrada nos indivíduos).

b) Deal e Kennedy ${ }^{12}$ avaliam a relação risco do investimento e a velocidade do feed-back do mercado.

- cultura macho (alto risco/rápido feed-back);

- cultura trabalho duro/diverte muito (baixo risco/rápido feed-back);

- cultura apostar sua companhia (alto risco/ lento feed-back);

- cultura processo (baixo risco/lento feed-back).

c) Sethia e Von Glinow ${ }^{13}$ enfatizam a preocupação por pessoas ou por performance (inspirados no Grid Gerencial), manejando o sistema de recompensas.

Cultura organizacional grandes temas em debate
- cultura apática - nem pessoas, nem per-

formance;

- cultura cuidadosa - pessoas;

- cultura exigente - performance;

- cultura integrativa - pessoas e performance.

d) R.Donnely ${ }^{14}$ observa a relação com o uso do planejamento.

- cultura excelente: usa planejamento;

- cultura fuzzy: mudança constante - descontinuidade negativa;

- cultura awful: crises constantes.

\section{CARÁTER ÚNICO}

É possível que duas ou mais organizações tenham a mesma cultura?

Jay Barney ${ }^{15}$ analisa a questão da perspectiva da influência da cultura na performance. Se a cultura pode ser entendida como uma fonte de vantagem competitiva, então ela deve ser: a)passível de avaliação quantitativa; b) ser rara; e, c) ser imitável, apenas imperfeitamente. Caso ela possa ser imitada perfeitamente, a vantagem estaria eliminada em pouco tempo.

Outra é a opinião de Joanne Martin e seus colaboradores ${ }^{16}$ para quem o assunto é paradoxal. Considerando que a cultura se expressa através de manifestações particulares, eles analisaram o caso das estórias organizacionais e perceberam que em muitas delas existia uma grande semelhança de conteúdo.

Já Akin e Hopelain ${ }^{17}$ desenvolveram uma análise partindo da existência de uma cultura de produtividade, cujos elementos são comuns, independente do tipo de organização onde ela exista. Os autores pesquisaram três organizações bastante distintas em termos de tecnologia, natureza da atividade, localização, tamanho, qualificações exigidas etc., e concluíram que o tipo de cultura era notadamente similar.

\section{MÚLTIPLAS CULTURAS}

Pode uma organização ter mais de uma cultura?

Para Kilmann e equipe ${ }^{18}$, os administradores que partilham o pressuposto X, de McGregor, tendem a admitir a existência de apenas uma cultura - a de cima para baixo ao contrário dos que endossam o pressuposto $Y$, onde várias culturas ou subculturas são admissíveis numa organização.

Meryl Louis ${ }^{19}$ assume que existem potencialmente várias culturas nos locais de trabalho. Deve-se considerar as raízes, ou lugares onde primeiramente os entendimentos são compartilhados e a extensão que a pene-
11. HANDY, Charles. Como Compreender as Organizações. Rio de Janeiro, Zahar, 1978; e HANDY, Charles. Deuses da Administracão. S.Paulo, Vértice, 1987. Veja também: HARRISON, R. "Understanding Your Organization's Character". Harvard Business Review, mai/jun, 1972; e HARRISSON R. "How to Describe Your Organization". Harvard Business Review, set/out. 1972

12. DEAL, T. \& KENNEDY, A. Op.cit.

13. SETHIA, N. \& VON GLINOW. M.A. "Arriving at Four Cultures by Managing the Reward System". In: KILMANN, R. et alii. $0 p$ cit.

14. DONNELY, R. "The Interrelationship of Planning With Corporate Culture on Creation of Shared Values". Managerial Planning, 32, mai-jun. 1984.

15. BARNEY, Jay. "Organizational Cultures: Can it be a Source of Sustained Competitive Advantage?" Academy of Manangement Review, 11(6), 1986.

16. MARTIN, Joanne et alii. "The Uniqueness Paradox in Organizational Stories". $A d-$ ministrative Science Quarterly, 28(3), set. 1983.

17. AKIN, G. \& HOPELAIN, D. "Finding the Culture of Productivity". Organizational Dynamics, 14, Winter, 1986.

18. KILMANN, R. et alii. "Five Steps in Understanding and Changing Culture". In: KILMANN, R. et alii. Op.cit.

19. LOUIS, Meryl. "Sourcing Workplace Cultures: Why, When and How". In: KILMANN, R. et alii. Op. cit.; e, também, LOUIS, Meryl. "An Investigator's Guide to Workplace Culture". In: FROST, P. et alii. Organizational Culture, Califórnia, Sage, 1985. 
20. Vide: DAVIS, Tim. "Managing Culture at the Bottom". in: KILMANN, R. et alii. Gaining Control of the: Corporate Culture. Op.cit:; WALKER, C.R \& GUEST, R.H. The Man on the Assembly Line. Cambridge, Harvard Press, 1952; AMSA P. "Organizational Culture and Work Group Behaviour: an Empirical Study". Journal of Management Studies, 23(3), mai. 1986; NICHOLSON, N. \& JOHNS, G. "The Absence Culture and the Psychological Contract - Who's in Control of Absence?" Academy of Management Review, 10(3), 1985; e KILMANN, R. "Five Steps for Closing Culture-Gaps". In: KILMANN, R. et alii. Gaining Control of the Corporate Culture. Op.cit.

21. Vide: SCHEIN, E. "Coming to a New Awareness of Organizational Culture". Sloan Manangement Review, Winter 1984; SCHEIN, E. "The Role of the Founder in Creating Organizational Culture". Organizational Dynamics, Summer. 1983; e SCHEIN, E. "How Culture Forms, Develops and Changes". 0p. cit. Outros autores: ANZIZU, J.M. de. "Cultura Organizativa: su Incidencia en el Funcionamiento y $\mathrm{De}-$ sarrolo de la Empresa". Alta Direcion (120) 1985; PETTIGREW, A. "On Studying Organizational Cultures". Administrative Science Quarterly, 24, dec. 1979.

22. MARTIN, J et alii. "Founders and Elusiveness of a Cultural Legacy". In: FROST, P. et alii. Op cit.: e também: MEYERSON,D. \& MARTIN, J "Cultural Change: an Integration of Three Different Views". Journal of Management Studies, 24(6), nov, 1987

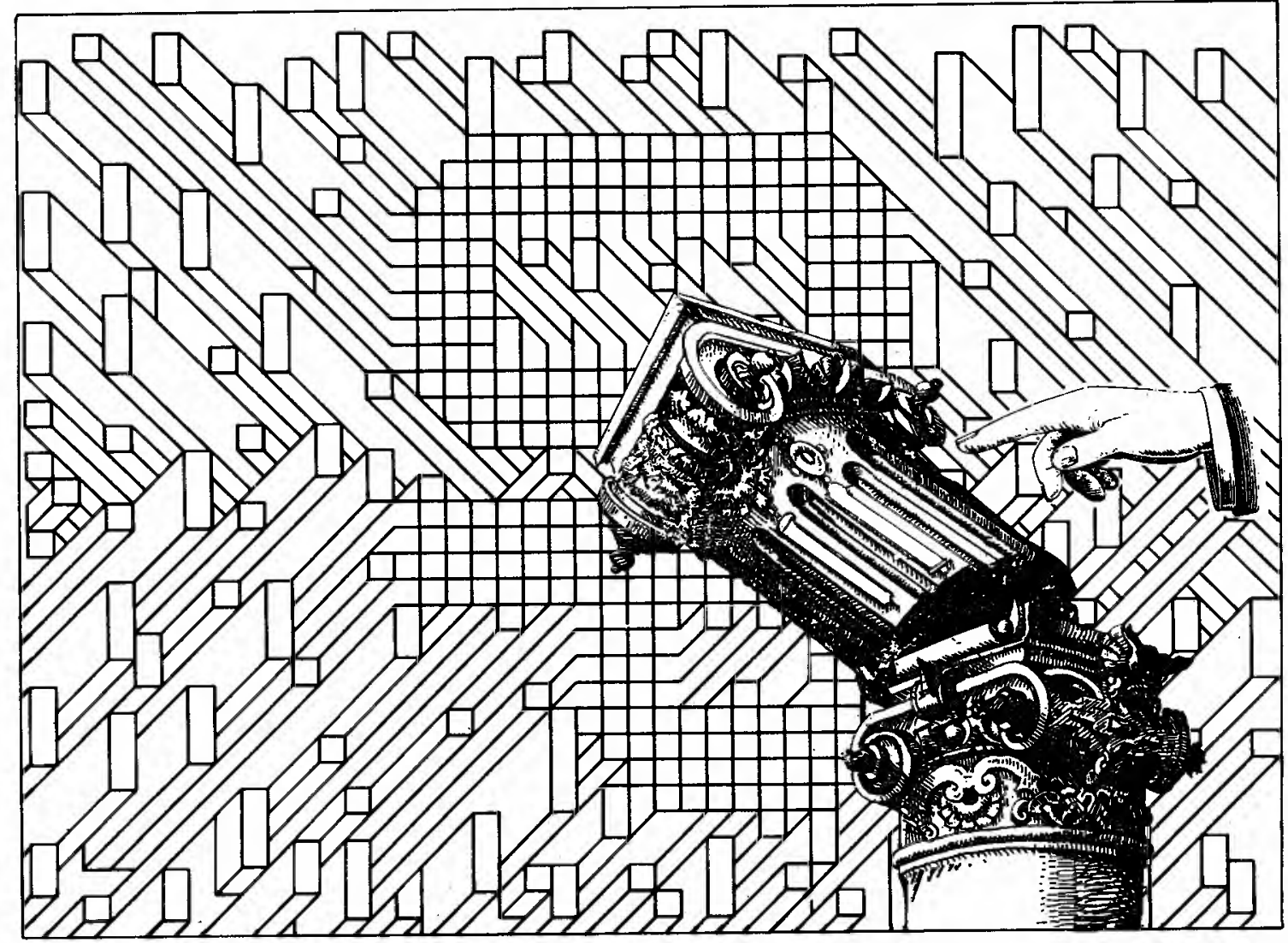

tração desses entendimentos atinge. É necessário verificar não apenas os conteúdos, o grupo e o relacionamento entre eles, mas também pensar na difusão e extensão dos conteúdos, na homogeneidade e consistência dos entendimentos e na estabilidade deles no tempo.

\section{A QUESTÃO DA CONTRACULTURA}

Não assumindo o termo "contracultura", mas resistências à cultura dominante, algumas poucas referências foram encontradas. A maior parte delas prende-se a diagnósticos e a recomendações corretivas para as situações detectadas. Algumas pesquisas foram realizadas enfatizando a problemática do absenteísmo ou ausência nos locais de trabalho ${ }^{20}$.

Será apenas uma coincidência a falta de pesquisas sobre o assunto, como no caso dos tabus?

\section{A INFLUÊNCIA DOS FUNDADORES}

A importância dos fundadores no estabelecimento da cultura é um dos poucos temas sobre o qual há consenso de opiniões, bem como uma grande semelhança nos argumentos de diversos pesquisadores ${ }^{21}$.

Uma opinião contrária é a de Joanne Mar- tin e sua equipe ${ }^{22}$, para quem os estudos organizacionais sobre a criação da cultura oferecem uma promessa sedutora para os fundadores, qual seja, a de que eles podem criar uma cultura à sua imagem, valores, pressupostos e visão de mundo. A perspectiva pessoal pode ser transformada num legado compartilhado que sobreviverá à sua morte ou à sua saída da organização.

Para esses estudiosos o resultado de pesquisas relacionadas com o assunto sugerem que esses pressupostos têm sido erroneamente colocados. Tal supersimplificação encobre o conflito interno e a diferenciação, características de organizações complexas como as atuais - eles admitem a existência de múltiplas culturas.

Ainda que reconhecendo o papel do fundador, o crédito a ele atribuído tem sido superestimado. Deve-se considerar a saliência do papel de líder, que faz com que ele figure como destaque na memória das pessoas, o que tende a causar suposições de responsabilidades; além disso, os fatores contextuais também têm sua importância na influência do conteúdo que é compartilhado. Nesse sentido, o fundador é também fundido num sistema moldado por forças que estão além de seu controle individual. 


\section{O PAPEL DA ADMINISTRAÇÃO DE RECURSOS HUMANOS}

Nenhum setor ou departamento isolado recebeu, na literatura consultada, tanta importância e destaque quanto o responsável pelos recursos humanos ${ }^{23}$. Tido como o verdadeiro guardião da cultura, ele exerce funções estratégicas, que promovem a aceitação, consolidação, manutenção e mudança culturais.

As atribuições típicas desse órgão ganham um novo brilho quando vistas à luz da análise cultural, passando a ser o canal de repasse, que materializa a sua consistência interna, através de:

- definição de perfis compatíveis com os valores que orientarão o recrutamento e a seleção; - desenho de programas de treinamento e de desenvolvimento, que passam a enfatizar a história da organização, incluindo depoimento dos heróis, e filmes que fazem o primeiro trabalho de socialização;

- elaboração dos sistemas de compensação e de status, que visam a premiar não somente a competência, mas a lealdade;

- definição de carreiras e critérios de avaliação, buscando reforçar a filosofia, crenças e mitos existentes;

- recuperação de "desviantes", esclarecendo e aconselhando quanto às normas vigentes;

- preparação de solenidades para celebrar heróis e destacar o comportamento exemplar; - veiculação de estórias que revigoram os valores, prioridades e mitos eleitos;

- definição e interpretação de mensagens adequadas, através da imprensa interna.

Com relação ao treinamento, nenhuma evidência é mais forte que a proliferação de universidades criadas pelas próprias empresas, tais como: Universidade Disney, Universidade Dana, e a famosa Universidade do Hamburger.

\section{CULTURA E PLANEJAMENTO ESTRATÉGICO}

A grande discussão sobre a existência e o reconhecimento de culturas organizacionais, principalmente na perspectiva funcionalista, ganha uma significação não somente como uma categoria de análise organizacional, mas, sobretudo, como um instrumento a ser melhor aproveitado na condução dos negócios. Diversos trabalhos na área de consultoria $\mathrm{e}$ na formulação de modelos visam a integrar outros sistemas organizacionais a fim de ampliar e viabilizar novas alternativas de sucesso. Nessas abordagens, ora a cultura

Cultura organizacional grandes temas em debate aparece como mais um subsistema que se liga à estrutura, estratégia, sistemas políticos e técnicos, ora como uma superestrutura que determina todos os demais componentes, englobando-os e fazendo o trabalho de síntese.

Como superestrutura, a cultura não parece tão fácil de ser manipulada e mesmo os consultores tidos como experts no assunto admitem a dificuldade de mudá-la, embora afirmem que isso possa ocorrer no longo prazo.

Por que levantamos a questão da mudança cultural nesse tópico?

Ora, reconhecer que as organizações "são" ou "têm" culturas e que estas são imutáveis, implicaria em reconhecer que os administradores se defrontam com algo que lhes foge ao controle. $\mathrm{Ou}$, pior ainda, em admitir que o sucesso ou fracasso de uma organização pode estar na dependência de um fator imprevisível. Uma vez que uma das mais relevantes funções dos administradores é procurar aumentar a previsibilidade do sistema que comandam, o reconhecimento da cultura como imutável seria acompanhado de uma forte dissonância cognitiva. É, pois, necessário que os teóricos dêem respostas práticas e úteis, e é nesse sentido que a ligação com o planejamento estratégico é feita.

Escolhemos os trabalhos de Desphandé e Parasuraman ${ }^{24}$ que fazem a ponte dos modelos teóricos de planejamento, como os conceitos de ciclo de vida e análise de portfólio (BCG), com a tipologia cultural desenvolvida por Deal e Kennedy, citada anteriormente.

Segundo a análise do ciclo de vida, todo produto e toda organização atravessam as seguintes fases: desenvolvimento e introdução no mercado, crescimento, maturidade e declínio. O modelo do BCG cria uma tipologia para classificar a carteira de negócios de uma dada organização considerando duas variáveis: taxa de crescimento do mercado e fatia relativa de mercado. $O$ resultado é uma matriz $2 \times 2$, em que os negócios se classificam em: crianças-problemas, estrelas, vacas leiteiras e abacaxi ou pepino. A tipologia de Deal e Kennedy é definida a partir do grau de risco do negócio e da velocidade de feedback recebida, gerando os tipos: cultura macho, aposte na sua companhia, trabalhar duro/divertir muito e cultura processo.

A correspondência entre o ciclo de vida do negócio e o BCG é a seguinte:

introdução - crianças problemas;

crescimento - estrelas;

maturidade - vacas leiteiras; e declínio - abacaxi ou pepino.

A ligação entre o ciclo de vida e o tipo cultural pode ser assim colocada:
23.Vide, entre outros: MARTIN, H. "Managing Specialized Corporate Culture"; SETHIA, N. \& VON GLINOW, "Arriving at Four Cultures by Managing Reward System", ambos in KILMANN, R. et alii. Gaining Control of the Corporate Culture. Op.cit.; POSNER et alii. "Shared Values Make a Difference: an Empirical Test of Corporate Culture". Human Resource Management, 24(3), Fall, 1985; ALBERT, M. \& SILVERMAN, M. "Making Management Phylosofay a Cultural Reality, part.2: Design Human Resource Program Accordingly". Personnel, (61), marabr. 1984; ULRICH, W. "HRM and Culture: History, Ritual and Myth". Human Resource Management, 23(2), Summer 1984; WILKINS, A. "The Creating of Company Cultures: the Roles of Stories and Human Resource System". Human Resource Management, 23(1) Spring, 1984; SOLBERG, S. "Human Resource Management in Action: Changing Culture Through Ceremony - an example from GM". Human Resource Management, 24(3), Fall, 1985; PASCALE, R. "Fitting New Employees Into the Corporate Culture". Fortune, mai. 28, 1984

24. DESHPANDE, R. \& PARASURAMAN, A “"Linking Corporate Culture to Strategic Planning". Business Horizons, 29, mai-jun, 1986. 


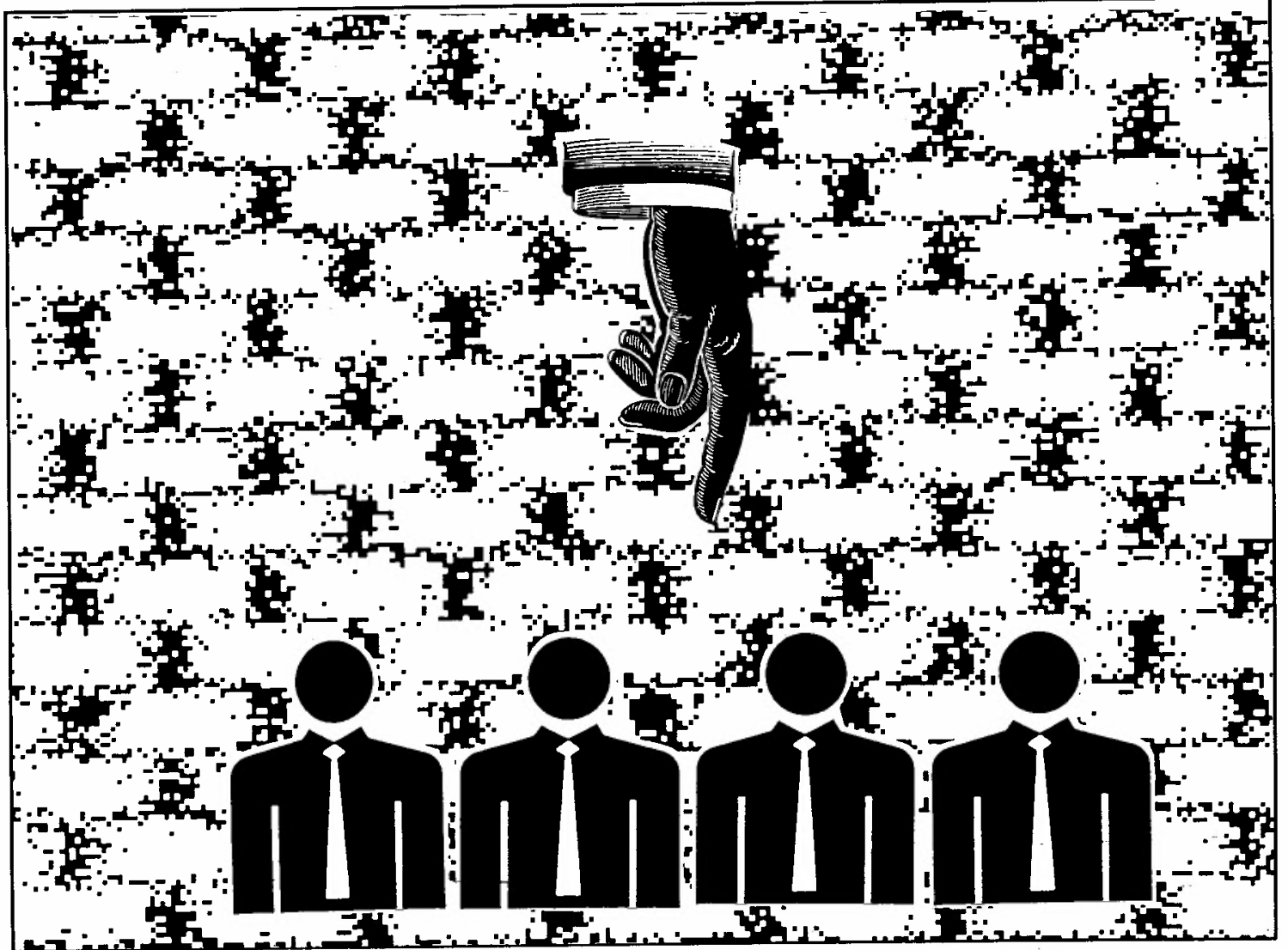

introdução - cultura macho (alto risco e rápido feedback);

crescimento - apostar na sua companhia (alto risco e lento feedback);

maturidade - trabalho duro/diverte muito (baixo risco e rápido feedback); e

declínio - cultura processo (baixo risco e lento feedback).

A junção de todas essas características é feita através do Contingency Model of Strategic Planning, que, a exemplo do BCG, consiste numa matriz $2 \times 2$ e tipifica a partir das taxas de crescimento do mercado e participação da firma no mercado. O resultado é a compatibilidade entre o estágio da organização e as culturas correspondentes mais adequadas a cada fase.

Também o trabalho de Schwartz e Davis ${ }^{25}$

25. SCHWARTZ, H. \& DAVIS, S. "Matching Corporate Culture and Business Strategy". Organizational Dynamics, Summer, 1981.

26. GORDON, G. "The Interrelationship of Corporate Culture to Industry Sector and Corporate Performance". In: KILMANN, R. et alii. Gaining Control of the Corporate Culture. Op.cit. truindo modelos teóricos-práticos que naturalizam seus valores, interesses e lógica.

$\hat{E}$, pois, com base nesses pressupostos que entendemos o debate dos diversos pesquisadores a respeito da relação entre cultura e performance. Supomos que grande parte da pesquisa gerada foi motivada pela crença segundo a qual a cultura cria impactos positivos (na visão gerencial) na organização; que a cultura é manejável no sentido de produzir a otimização de resultados. Entendemos, como evidência dessa crença, a quantidade de bestsellers e a proliferação de empresas e pacotes de consultoria especializados no assunto.

Alguns autores não crêem que exista uma influência da cultura no desempenho da organização; no entanto, em termos de expressão quantitativa, é maior a produção dos que defendem a posição contrária, incluindose os autores de best-sellers mencionados anteriormente.

As pesquisas realizadas por George Gordon $^{26}$, envolvendo mais de 50.000 respostas de executivos de empresas estáveis, dinâmicas e financeiras, concluíram que, sendo a cultura definida pelos administradores a partir de uma visão estratégica em consonância com o seu meio ambiente, ela é, sem dúvida, uma variável que gera forte impacto no desem- 
penho organizacional.

Esta é, também, a opinião de Daniel Denison $^{27}$, rebatendo a afirmativa de alguns pesquisadores sobre a não-evidência de relação positiva e mensurável entre cultura e performance organizacional.

\section{MUDANÇA CULTURAL}

Não é consenso entre os pesquisadores que a cultura possa mudar. Até os que defendem a condição de mudança assumem que o processo não é simples, não é barato e não se faz sem causar traumas. Existe uma concordância implícita a respeito de a cultura ser conectada a outros elementos organizacionais que também sofrerão alterações caso haja uma mudança cultural, como a estratégia, a estrutura, habilidades, sistema de recompensas, entre outros ${ }^{28}$.

O que se entende por mudança cultural é a definição de um novo rumo, uma nova maneira de fazer as coisas, alicerçada em novos valores, símbolos e rituais. É a AT\&T se assumir num mercado competitivo; é a Pepsi Co. decidir que ser o segundo lugar no ranking não é mais o bastante.

Deal e Kennedy ${ }^{29}$ comentam que a mudança cultural é a parte mais difícil de uma transformação cultural e que esse fato é, em geral, subestimado não só em relação ao tempo, mas também em relação aos custos envolvidos. Para eles, pelo menos, em cinco situações a mudança deve ser considerada pela alta administração:

a) quando estão ocorrendo mudanças fundamentais no ambiente (caso AT\&T);

b) quando a indústria é altamente competitiva e o ambiente é mutável (Digital, Intel etc.); c) quando a companhia é medíocre e vem acumulando resultados cada vez piores;

d) quando a companhia está em vias de tornar-se uma grande corporação (entrar para a lista das 1000 da Fortune é um critério);

e) quando a companhia está crescendo rapidamente e uma massa enorme de trabalhadores está sendo absorvida.

Os autores sugerem alguns passos para a administração da mudança:

$\left.1^{2}\right)$ reconhecer que o consenso dos pares será a questão de maior influência para a aceitação e boa vontade com o processo;

$2^{\circ}$ ) exprimir e enfatizar a confiança (mão dupla) em todos os assuntos relacionados com a mudança;

$\left.3^{9}\right)$ pensar na mudança como a construção de habilidades e concentrar no treinamento uma parte importante do processo;

Cultura organizacional grandes temas em debate $\left.4^{\circ}\right)$ dar tempo para que as pessoas se acostumem e consolidem a mudança; $e$ $5^{\circ}$ ) encorajar as pessoas a se adaptarem à idéia de que a mudança faz parte do mundo real que as rodeia.

É necessário, ainda, incluir o comprometimento dos heróis, o reconhecimento do inimigo externo; fazer dos rituais de transição os pivôs da mudança; treinar novos valores e padrões comportamentais; não perder de vista que a mudança foi promovida pelos insiders; construir símbolos tangíveis da nova direção e insistir que a segurança do emprego está assegurada no processo de transição.

Sobre as dificuldades e conseqüências da mudança cultural, Terrence Deal ${ }^{30}$ levanta alguns pontos interessantes com base em suas observações em diversas empresas - incluindo a AT\&T. Ele diz que mudanças dessa natureza provocam sentimentos de perda e dor. Diante de situações em que os indivíduos experimentam a perda de sentido e que geram desconforto psicológico, eles tendem a reagir, ou agarrando-se ao passado ou envolvendose com o presente de forma a negar a perda. A mudança cultural provoca essas reações, à medida que os símbolos criados para dar sentido à vida foram quebrados, negados ou substituídos. $\mathrm{O}$ autor descreve alguns depoimentos de indivíduos confusos, abalados, tristes e vazios, após mudanças nas organizações em que trabalhavam.

Em se tratando de algo reconhecidamente difícil de mudar, e quando mudado, provocando sentimentos de desorientação coletiva, a cultura organizacional dá o seu próprio testemunho a respeito da extensão em que ela afeta as pessoas numa organização, de quão internalizados podem ser os seus controles $\mathrm{e}$ de como o envolvimento organizacional invade outras instâncias privadas do indivíduo.

\section{CONTEXTO NACIONAL E ORGANIZAÇÕES TRANSNACIONAIS}

Vivemos o mundo das grandes organizações, sem barreiras geográficas. É verdade também que essas organizações carregam consigo uma matriz sócio-cultural que foi gestada em seus países de origem.

Até que ponto um dado contexto cultural é fator limitante da ação dessas organizações? Que informações extras são necessárias sobre esse contexto? Como essas informações são utilizadas para aumentar a compatibilidade entre as culturas dessas organizações e as dos países que as hospedam?

O trabalho desenvolvido por Geert Hofstede $^{31}$ é um dos mais ricos sobre essas
27. DENISON, D. "Bringing Corporate Culture to the Bottom Line". Organizational Dynamics, 13, Aut. 1984.

28. Grande parte da literatura dedica-se a descrever casos de mudancas bem-sucedidas. Nesse sentido, ver 0 artigo de DYER JR., sobre a GM, LeviStrauss, NCR e The Balfour Co.; de TUNSTALL, sobre a AT\&T; de GORDON, sobre a Home Life Insurance; e o de SATHE sobre a Cummings Engine. Todos publicados em KILMANN $R$ et alii. Gaining Control of the Corporate Culture. Op. cit. Uma experiência de fracasso é descrita por REYNOLDS, P. Across the Board. Out. 1986. Dúvidas são levantadas nos artigos da Business Week, de 27.10 .85 e de 14.05.84.

29. DEAL, T. \& KENNEDY, A Op.cit.

30. DEAL, T, “Cultural Change: Opportunity, Silent Killer, or Metamorphosis?" In: KILMANN, R. et alii. Gaining Control of the Corporate Culture. Op. cit.

31. 0 autor tem vários artigos publicados sobre o tema porém as idéias centrais desenvolvidas encontram-se reunidas no livro Culture Consequences: International Differences in Work-Related Values. Beverly Hills, Sage Publ. 1980. 
questões e um dos mais regularmente citados. Interessado na interação de valores organizacionais e nacionais, ele realizou uma ampla pesquisa, envolvendo 40 países, durante quase quinze anos. Dela resultou a identificação de quatro dimensões de valores que, segundo ele, explicam cerca de $50 \%$ das diferenças entre os padrões de valores relacionados com o trabalho.

Vejamos as dimensões:

a) Distância de poder: extensão na qual a sociedade aceita o fato de que o poder é distribuído desigualmente nas organizações e na própria sociedade, onde existem privilégios e a autoridade pessoal absoluta é aceita.

b) Evitar incertezas: extensão na qual a sociedade se sente ameaçada por situações incertas e ambíguas. As sociedades apresentam diferentes coeficientes de aversão ao risco.

c) Individualismo versus coletivismo: a maneira como o indivíduo está ligado à estrutura social; se esse laço é mais rígido ou mais flexível, no sentido de oferecer oportunidades para a exibição de comportamentos individualistas. Basicamente, a idéia do nós em contraposição ao eu.

d) Masculino versus feminino: extensão na qual a sociedade privilegia a realização, heroísmo, determinação pessoal e sucesso material, em oposição à preferência por relacionamentos, modéstia, cuidado com os outros, qualidade de vida etc.

Considerando que as organizações desenvolvem suas próprias culturas e sistemas predominantes de valores, Hofstede admite que as subsidiárias estrangeiras de empresas multinacionais acabam por desenvolver uma cultura híbrida. No caso de multinacionais bem integradas, com uma cultura forte, podese verificar uma grande similaridade entre os seus membros: "ele é um típico homem Shell mesmo que seja japonês".

Isolando as dimensões distância de poder e evitar incertezas, $o$ pesquisador apresenta uma classificação dos diversos países de acordo com índices "alto" e "baixo" para cada dimensão, formando uma matriz. Para cada quadrante é sugerido um modelo específico de controle, compatível com o que está implícito na mente das pessoas sobre o que elas acreditam que uma organização possa ser.

As dimensões individualismo $x$ coletivismo e masculino $x$ feminino também classificam os países pesquisados. $O$ pressuposto de Hofstede é que essas dimensões afetam diretamente o autoconceito dos indivíduos.

Uma das implicações dessa pesquisa é que as organizações transnacionais podem prever determinados problemas de ordem cultural local, e a eles responder antecipadamente com o desenho de estruturas de controle, explícitas ou não, de forma a conquistar a aceitação e a lealdade mais facilmente. Significa também um maior domínio sobre possiveis reivindicações dos grupos internos, maior previsibilidade do tipo de satisfações que podem oferecer para abafar essas reivindicações, ou mesmo evitar que elas aflorem.

\section{CONCLUSÕES}

Procuramos dar uma visão geral sobre onde o debate a respeito da cultura organizacional tem se concentrado, usando basicamente a produção acadêmica norte-americana, por uma questão de acesso.

$\mathrm{O}$ contato com diferentes abordagens reforçou o nosso pressuposto, segundo o qual a cultura exerce funções de controle extremamente sofisticadas. E são essas funções, que preenchem de uma maneira soft, que têm tornado o assunto tão atraente para os teóricos e os práticos da administração.

O desenvolvimento e a sedimentação de uma cultura organizacional "forte e coesa" busca restaurar perdas psicológicas nos indivíduos que nela trabalham, repondo um quadro de valores, crenças e pressupostos, orientador de um comportamento coletivo conveniente aos seus objetivos.

A maneira sutil como uma organização cultural "forte/excelente" se une em torno de formas específicas de pensar e agir, criando de si uma imagem positiva e onipotente, conforma $o$ indivíduo às normas estabelecidas, conquistando-lhe a adesão e lealdade na sua reprodução. É nessa conquista do afetivo que ela marca sua diferença enquanto forma de controle. E por admiração e por amor, muitos "sacrifícios" são justificados, até porque se torna honra fazer parte dessa organização. Nesse sentido o hino da IBM $^{32}$ é bem ilustrativo:

\section{EVER ONWARD - EVER ONWARD}

That's the spirit that brought us fame! We're big, but bigger we will be We can't fail for all can see That to serve humanity has been our aim Our products are now known in every zone Our reputation sparkles like a gem We've fought our way through and new Fields we're sure to conquer too Forever onward IBM ".
32. Citado em DEAL, T \& KEN NEDY, A. Op. cit, p. 115. 